\title{
Article
}

\section{Pharmacists in Pharmacovigilance: Can Increased Diagnostic Opportunity in Community Settings Translate to Better Vigilance?}

Rutter, Paul, Brown, David, Howard, Justine and Randall, Christine Available at http://clok.uclan.ac.uk/14204/

Rutter, Paul ORCID: 0000-0003-4106-1515, Brown, David, Howard, Justine and Randall, Christine (2014) Pharmacists in Pharmacovigilance: Can Increased Diagnostic Opportunity in Community Settings Translate to Better Vigilance? Drug Safety, 37 (7). pp. 465-469. ISSN 0114-5916

It is advisable to refer to the publisher's version if you intend to cite from the work. http://dx.doi.org/10.1007/s40264-014-0191-6

For more information about UCLan's research in this area go to http://www.uclan.ac.uk/researchgroups/ and search for <name of research Group>.

For information about Research generally at UCLan please go to http://www.uclan.ac.uk/research/

All outputs in CLoK are protected by Intellectual Property Rights law, including Copyright law. Copyright, IPR and Moral Rights for the works on this site are retained by the individual authors and/or other copyright owners. Terms and conditions for use of this material are defined in the policies page. 


\section{Pharmacists in Pharmacovigilance: Can Increased Diagnostic Opportunity in Community settings Translate to Better Vigilance?}

Paul Ruttera, David Brown ${ }^{\mathrm{b}}$, Justine Howard ${ }^{\mathrm{c}}$, Christine Randallc

aprofessor of Pharmacy Practice

School of Pharmacy, University of Wolverhampton

MA Building, Wulfruna Street

Wolverhampton, WV1 1SB, UK

${ }^{b}$ David Brown

Professor of Pharmacy Practice

School of Pharmacy and Biomedical Sciences, University of Portsmouth

St. Michael's Building, White Swan Road

Portsmouth, PO1 2DT, UK

${ }^{c}$ Christine Randall

Senior Medicines Information Pharmacist

c Justine Howard

Adverse Drug Reaction Information Officer

North West Medicines Information Centre/Yellow Card Centre North West

70 Pembroke Place

Liverpool, L69 3GF, UK

*Correspondence to Prof P. Rutter; Tel: 01902 322173, Fax 01902 322714, E-mail:

paul.rutter@wlv.ac.uk

\section{Abstract}

The pharmacy profession has undergone substantial change over the last two to three decades. Whilst medicine supply still remains a central function, pharmacist's roles and responsibilities have become more clinical and patient-focused. In community (primary care), pharmacists have become important providers of healthcare as Western healthcare policy advocates patient self-care. This has resulted in pharmacists taking on greater responsibility in managing minor illness and the delivery of public health interventions. These roles require pharmacists to more fully use their clinical skills, and often involve diagnosis and therapeutic management. Community pharmacists are now, more than ever before, in a position to identify, record and report medication safety incidents. However, current research suggests that diagnostic ability of community pharmacists is questionable and they infrequently report to local or national schemes. The aim of this paper is to highlight current practice and suggest ways in which community pharmacy can more fully contribute to patient safety.

Running Head: Increasing Pharmacovigilance by community pharmacists 


\section{Key Points}

Community pharmacists' scope of practice is widening which demands greater use of clinical and diagnostic skills to provide more patient focused clinical services.

Patient advocacy and clinical accountability need strengthening within pharmacy education to allow practitioners to take responsibility for their patients, and ensure patient safety through better vigilance

As community pharmacists embark on this role transition there is an opportunity to engender a culture of reporting that is supported by organisational change to ensure sustainability 


\section{Community Pharmacists in Pharmacovigilance: Can Improved Diagnostic Ability Translate to Better Vigilance?}

\section{Introduction}

Healthcare systems across the world, and in particular Western healthcare systems, have undergone major reforms in response to political and economic pressures [1-6]. This has resulted in attempts to maximise existing resources, both financial and staffing, to improve delivery of effective and efficient healthcare [7-8]. Healthcare policies of many countries now encourage the public to take control of their own health. Community pharmacists have been identified as a very accessible professional group that can optimise patient use of medicines and facilitate patient self-care [9-11]. This will require community pharmacists to combine their traditional role of medicine supply (and medicines expertise) $[12,13]$ with the need to provide additional patient-focused services [14-16]. This re-alignment of job role has started to see an expansion in their scope of practice, involving public health services [1719], inclusion in to national systems to report adverse drug reactions [20], and granting of prescribing rights [21-23].

The self-care concept has been supported by governments making more medicines freely available. Most medicines that have been 'switched' from prescription control are to relieve signs and symptoms associated with acute episodes of illness but recently for the management of long-term conditions (e.g. statins and tamsulosin) have also been made available..

Australia, Germany, UK, and the US are seen as world leaders in medicine switching [24]. For example, over 90 prescription medicines have been made non-prescription in the UK between 1983 and 2013; in the US, from 1976 to 2003, there were 71 prescription to over-the-counter (OTC) switches [25]. Community pharmacists therefore find themselves the custodians of an increasing arsenal of medicines which can be used to manage a wider range of signs and symptoms. This affords pharmacists opportunities to monitor for adverse events associated with these products as well as identifying drug-induced signs and symptoms.

\section{Diagnostic Ability of Community Pharmacists}

The role of 'responding to symptoms' has been associated with community pharmacy practice for decades but with increased medicine deregulation (including European-wide deregulation, for example orlistat [26]) and role expansion, pharmacists need to be well schooled in how to diagnose. However, limited research has assessed community pharmacists' ability to be a good diagnostician. Pharmacy researchers have primarily assessed what questions pharmacists ask and the actions they take when dealing with standardised patient scenarios, [27, 28] or what influences pharmacist selection of non-prescription medicines [29]. Only recently has exploratory research begun to investigate the process by which they make a diagnosis [30, 31]. Data suggest that community pharmacists rely heavily on protocol-driven questioning that may lead to mis-diagnosis. Indeed consumer organisations have criticised the diagnostic ability of pharmacists when assessed using mystery shoppers [32-25]. In pharmacy's defence, the underpinning knowledge and skills required to diagnose from a patients presenting signs and 
symptoms are relatively recent introductions to pharmacy undergraduate curricula [36], and even when elements of diagnosis are covered, for example, physical examination (which is a pre-requisite for course accreditation in the US) it is not necessarily in the context of making a diagnosis [37]. In many European curricula it still does not feature [38]. Given the development of contemporary pharmacy practice and current research findings there seems to be a need to equip current and future pharmacists with better diagnostic skills. In the UK, this 'skills shortage' of practitioners has been partially recognised with the launch of a national learning and development framework on consultation skills in April 2014 [39].

\section{Community Pharmacist Contribution to Pharmacovigilance}

Many of the roles and responsibilities being afforded to community pharmacists require greater use of clinical skills, especially those involving consultation, diagnosis and therapeutic intervention [40]. What is unknown is will these facilitated self-care models effect how community pharmacists contribute to medicines safety? Looking at current practice it appears that reporting by community pharmacists is low, especially when it is voluntary. Two examples are used here for illustration. ADR reporting by pharmacists is now well established in many countries [20], and where data are available, community pharmacists tend to be worse at reporting than their hospital colleagues. [41-43] Barriers to poor reporting are well documented [44-45], but lack of financial incentive has been additionally cited by community pharmacists [46]. A further example is drawn from the UK National Reporting and Learning System (NRLS), which captures patient safety incidents for England and Wales. A 2006 study found that pharmacy staff were unlikely to report adverse events, regardless of severity. A lack of understanding about reporting and mistrust about its purpose were given as reasons for non-reporting [47]. This situation appears not to have markedly improved in that NRLS statistics for 2011-12 showed community pharmacists reported 1343 incidents compared to 3967 by primary care doctors [48]. Incidents reported by community pharmacists were almost entirely based $(96 \%$ of reports) on medicine safety issues (compared to $18 \%$ for doctors), which does highlight the highly focused nature of pharmacy reporting.

When incentivised, it appears community pharmacists are more likely to document and report medicine safety issues. Two new medicine adherence services (New Medicines Services in the UK and Home Medicines Review in Australia) allow pharmacists to assess patient understanding and use of new and established medicines [49, 50]. Both services require each patient consultation to be documented and form the basis for remuneration and require pharmacists to report on medication safety issues. In the first nine months after the New Medicines Service was launched, ADR reporting increased by $120 \%$ [51]. 


\section{Improving Pharmacovigilance from Community Pharmacies}

Current medication/patient safety incident reporting rates are low. There is a need within community pharmacy to improve reporting - and of course learning, from such incidents. The key question is how community pharmacists' can be encouraged to report more given that role expansion will provide increased diagnostic opportunity. We believe that changes need to be made both within the pharmacy profession and to existing healthcare structures.

\subsection{The Profession}

Pharmacy has, and in some countries still is, a predominantly science-based course, yet if pharmacy education is to keep pace with current and future changes in practice then curricula have to adapt to become more patient focused. This will not necessarily be about providing knowledge - for example pharmacovigilance is reasonably well understood and covered at undergraduate level [52-54]. Teaching focus needs to be patient centred and will require students to develop attributes which reinforce the need to put patient welfare first. Pharmacy could learn from other professions, such as medicine in this regard [55]. From such foundations, concepts of clinical reasoning, patient safety and clinical accountability can be instilled. Concepts can then be translated in to practice by actions which include diagnosis, shared decision making, documentation and reporting. To ensure this behaviour becomes routine, pharmacy students should have greater exposure to first hand clinical practice. The extent to which this is happening internationally varies enormously; but in general the experiential opportunities afforded to pharmacy students is much less than other healthcare students. This exposure to practice and working with others in multidisciplinary environments will foster and consolidate a more patient focused approach to care - something that is not always apparent in pharmacy curricula.

Inevitably, educational changes take time to percolate in to clinical practice, creating a need for postgraduate opportunities to bridge this gap. One such example is courses to become an independent prescriber where clinical accountability and diagnostic ability have greater prominence [56]. Research undertaken with prescribing pharmacists has largely focused on their attitudes toward this new role but one study found that prescribing pharmacists were more likely to report suspected ADRs than nurse prescribers [57]. Whether training to be a prescriber affects attitude toward pharmacovigilance is unknown; more studies are required to establish if independent prescribers routinely incorporate patient safety reporting in to their practice. If this is the case then there is a compelling argument to instruct undergraduates in a similar fashion.

Finally, it must be acknowledged that potential barriers to practice change are pharmacists themselves. Work has highlighted time, money and lack of interest as constraints yet when models have been trialed to remove such obstacles sustained practice change has not resulted $[58,59]$. Evidence also suggests that pharmacists are reluctant to move away from a supply function and shy away from taking responsibility for the patient. [60-62]. 


\subsection{Organisational Change}

The environment in which community pharmacists work hampers their ability to better contribute to medication and patient safety. New ways of working need to be incorporated in to clinical practice. Changes in the way services are delivered and integrated in existing healthcare structures need consideration. Having access to shared care records would be one way in which primary healthcare services could be more closely aligned. Access to records would enable, and may encourage, community pharmacists to document, report and reflect on their activities when facilitating patient self-care. This could be further strengthened by introducing formal referral mechanisms to medical practitioners following pharmacist diagnosis to allow follow-up and determine outcomes. This may necessitate patient registration with a named community pharmacy. Registration at a community pharmacy is not unknown as exemplified by the Scottish minor ailments service [63]. Such changes need to be incentivised. Evidence suggests that incentives do influence community pharmacists' activity. When providing contracted services (through government or medical insurance) the remuneration models need to move away from prescription supply to activity that has reward for providing more patient-focused activities. Such models are being introduced, although the inclusion of pharmacovigilance-type activities is low $[50,64,65]$. For private transactions (e.g. over-the-counter consultations) changes to legislation may hold the key to increased documentation and incident reporting even though there is evidence that educational intervention around ADRs has a positive effect on reporting rates [66]. In all likelihood a combination of incentive and legal compulsion will be required. Regardless of approach taken the success and speed of adoption will depend on strong leadership, appropriate resource and creation of sustainable infrastructures.

\section{Conclusion}

Community pharmacy is in transition from a medicine supply service to providing cognitive services as self-care policies in Western societies become more prominent. The workforce is currently poorly prepared to take on some of these roles that involve the ability to diagnose and accept clinical accountability. To ensure patient safety the profession needs to develop a patient centred, medicines focused culture that embraces reporting medicine safety issues. This must be supported by healthcare policy that allows better integration of community pharmacy services.

\section{Ethical standards}

The manuscript does not contain clinical studies or patient data.

\section{Conflict of Interest}

We state that we have full control of all primary data and that we agree to allow the journal to review their data if requested.

David Brown is an honorary research fellow of the UK Drug Safety Research Unit, Southampton. This is an associate organisation of the University of Portsmouth.

Funding: None

Competing interests: None 
References

1. Commonwealth of Australia. Building a 21st Century Primary Health Care System: Australia's First National Primary Health Care Strategy. Canberra, ACT: Department of Health and Ageing, 2010 [online]. Available from URL:

http://www.health.gov.au/internet/yourhealth/publishing.nsf/Content/reportprimaryhealth. [Accessed 2014 Jan 23]

2. Commonwealth of Australia. A National Health and Hospitals Network for Australia's Future: Delivering The Reforms. Canberra, ACT: Commonwealth of Australia, 2010 [online]. Available from URL: http://www.health.gov.au/internet/yourhealth/publishing.nsf/Content/DeliveringT heReforms. [Accessed 2014 Jan 23]

3. Black N. Can England's NHS survive? N Engl J Med 2013 Jul 4;369(1):1-3.

4. Keyhani S, Falk R, Howell EA, Bishop T, Korenstein D. Overuse and systems of care: a systematic review. Med Care 2013;51(6):503-8.

5. Marchildon G. Canada: Health system review. Health Syst Transit 2013;15(1):1-179.

6. 2012 - the NZ Health Strategy, Health Targets, Better Sooner More convenient [online]. Available from URL:

http://www.health.govt.nz/system/files/documents/publications/better-soonermore-convenient-health-care 0.pdf [Accessed 2014 Jan 23]

7. NHS and social care workforce: meeting our needs now and in the future? [online]. Available from URL:

http://www.kingsfund.org.uk/sites/files/kf/field/field publication file/perspectives -nhs-social-care-workforce-jul13.pdf [Accessed 23 Jan 2014]

8. 2009 Health Workforce New Zealand. [online]. Available from URL: http://healthworkforce.govt.nz/annual-plans [Accessed 2014 Jan 23]

9. Paudyal V, Hansford D, Cunningham S, Stewart D. Pharmacy assisted patient self care of minor ailments: A chronological review of UK health policy documents and key events 1997-2010. Health Policy 2011:101:3 253-259.

10. Pharmacy Guild of Australia [online]. Available from URL:

http://www.guild.org.au/docs/default-source/public-documents/news-andevents/2013-federal-election/vital-facts-on-community-pharmacyjune2013 441678 2.pdf [Accessed 2014 May 26]

11. Planning a research study? - think community pharmacy RPS [online]. Available from URL: http://www.rpharms.com/news-story-downloads/thinkpharmacy---promotional-leaflet.pdf [Accessed 2014 Jan 23]

12. Jesson JK, Langley CA, Wilson KA, Hatfield K. Science or practice? UK undergraduate experiences and attitudes to the MPharm degree. Pharm World Sci 2006; 28: 278-283. 
13. NHS Choices - Pharmacy services. [online]. Available from URL: http://www.nhs.uk/NHSEngland/AboutNHSservices/pharmacists/Pages/pharma cistsandchemists.aspx. [Accessed 2014 Jan 23]

14. Department of Health. Pharmacy in England: Building on Strengths Delivering the Future. London: Crown Copyright, 2008 [online]. Available from URL:

http://webarchive.nationalarchives.gov.uk/+/www.dh.gov.uk/en/Consultations/Cl osedconsultations/DH 087324. [Accessed 2014 Jan 23]

15. Canadian Pharmacists Association Task Force on a Blueprint for Pharmacy. Blueprint for Pharmacy: Designing the Future Together. Ottawa: CPhA, 2008 [online]. Available from URL:

http://www.pharmacists.ca/index.cfm/pharmacy-in-canada/blueprint-forpharmacyl [Accessed 2014 Jan 23]

16. Pharmaceutical Society of New Zealand. Focus on the Future: a Tenyear Vision for Pharmacists in New Zealand 2004-2014. Wellington:

Pharmaceutical Society of New Zealand, 2004 [online]. Available from URL: http://psnz.org.nz/public/home/documents/10 yea plan.pdf [Accessed 2014 Jan 23]

17. Healthy Lives, Healthy People - our strategy for public health in England. Department of Health (2010) [online]. Available from URL: https://www.gov.uk/government/publications/healthy-lives-healthy-people-ourstrategy-for-public-health-in-england. [Accessed 2014 Jan 23]

18. Guide for public health - Partnering with Pharmacists in the Prevention and Control of Chronic Diseases. National Center for Chronic Disease Prevention and Health Promotion [online]. Available from URL: http://www.cdc.gov/dhdsp/programs/nhdsp program/docs/pharmacist guide.pd f. [Accessed 23 Jan 2014]

19. Claim and Confirmation for Home Medicines Review Service [online]. Available from URL: http://www.medicareaustralia.gov.au/provider/pbs/fifthagreement/files/4915-1303en.pdf [Accessed 2014 Jan 23]

20. van Grootheest K, Olsson S, Couper M, Jong-van den Berg L.

Pharmacists' role in reporting adverse drug reactions in an International perspective. Pharmacoepidemiol Drug Saf 2004;13:457-64.

21. Emmerton L, Marriott J, Bessell T, Nissen L, Dean L. Pharmacists and prescribing rights: review of international developments. J Pharm Pharm Sci 2005;8(2):217-25.

22. Pharmacy Council of New Zealand. Pharmacist prescribers [online]. Available from URL:

http://www.pharmacycouncil.org.nz/cms display.php?st=1\&sn=232. [Accessed 2014 Jan 23]

23. California's pharmacist provider status bill passes state Senate. [online]. Available from URL:

http://www.pharmacist.com/CEOBlog/california\%E2\%80\%99s-pharmacistprovider-status-bill-passes-state-senate [Accessed 2014 May 23] 
24. World self-medication Industry. SWITCH. Prescription to nonprescription medicines switch. WSMI 2009 [online]. Available from URL: http://www.wsmi.org/pdf/wsmi_switchbrochure.pdf [Accessed 2014 Jan 23] 25. Wertheimer AI, Santella TM. Medication errors associated with overthe-counter drugs; prevalence and reduction strategies. J Pharmaceut Finance Econ Pol 2007;15:109-44.

26. European Medicines Agency - Alli [online]. Available from URL: http://www.ema.europa.eu/ema/index.jsp?curl=pages/medicines/human/medici nes/000854/human med 000641.jsp [Accessed 2014 May 26]

27. Lansam GD, Kropff MA. Community pharmacists' assessments and recommendations for treatment in four scenarios. Ann Pharmacother 1998;32:409-416.

28. Horsley E, Rutter P, Brown D. Evaluation of Community Pharmacists' Recommendations to Standardized Patient Scenarios. Ann Pharmacother 2004:38;1080-1085.

29. Hanna L, Hughes CM. 'First, do no harm': Factors that influence pharmacists making decisions about over-the-counter medication: A qualitative study in Northern Ireland. Drug Saf 2010;33(3):245-255.

30. Iqbal N, Rutter P. Community Pharmacists Reasoning When Making a Diagnosis: A think-aloud study think aloud IJPP 2013; 21: Supplement 2, 17-8.

31. Rutter P, Patel J. Decision Making by Community Pharmacists When Making an Over-the-counter Diagnosis in Response to a dermatological presentation. SelfCare 2013;4:125-133.

32. Consumers' Association. Pharmacists: how reliable are they? Which Way to Health? 1991; (12):191-4.

33. Consumers' Association. Vital checks are still not being made. Which Way to Health? 1994;(12):196.

34. Consumers' Association. Counter advice. Which Way to Health? 1999;(3):22-25.

35. Which? Pharmacies get test of own medicine.[online]. Available from URL:

www.which.co.uk/news/2008/09/pharmacies-get-test-of-own-medicine-157330/. [Accessed 2014 Jan 23]

36. Future pharmacists Standards for the initial education and training of pharmacists. [online]. Available from URL:

http://www.pharmacyregulation.org/sites/default/files/GPhC Future Pharmacist s.pdf

37. Accreditation Council for Pharmacy Education. Accreditation Standards and Guidelines for the Professional Program in Pharmacy Leading to the Doctor of Pharmacy Degree. [online]. Available from URL: https://www.acpeaccredit.org/pdf/FinalS2007Guidelines2.0.pdf [Accessed 2014 Jan 23]

38. $\quad$ Pharmine -Pharmacy Education in Europe [online]. Available from URL:

http://enzu.pharmine.org/media/filebook/files/PHARMINE\%20Final\%20Report\% 20Public\%20Part.pdf _[Accessed 2014 Jan 23]

39. CPPE Consultation skills; meeting the new practice standards for pharmacy [online]. Available from URL:

http://www.cppe.ac.uk/learning/Details.asp?TemplatelD=Consult-W-

03\&Format=W\&ID=26\&EventID=- [Accessed 2014 Jan 23] 
40. Brown D, Portlock J, Rutter P. Services to support the Healthy Living Pharmacy - a literature review. Int J Clin Pharm 2012; 34(3): 399-409.

41. Hadi MA. Impact of pharmacist recruitment on ADR reporting: Malaysian experience. Southern Med Review 2011;4:102.

42. Kimura T, Matsushita Y, Kao Yang YH, Choi NK, Park BJ. Pharmacovigilance systems and databases in Korea, Japan, and Taiwan. Pharmacoepidemiol Drug Saf 2011;20:1237-45.

43. Granas AG, Buajordet M, Stenberg-Nilsen H, Harg P, Horn AM. Pharmacists' attitudes towards the reporting of suspected adverse drug reactions in Norway. Pharmacoepidemiol Drug Saf 2007;16:429-434.

44. Pharmacist reporting of serious adverse drug events to the Food and Drug Administration. Gavaza P, Brown CM, Lawson KA, Rascati KL, Steinhardt M, Wilson JP.J Am Pharm Assoc (2003). 2012 Sep-Oct;52(5):e109-12.

45. Su C, Ji H, Su Y. Hospital pharmacists' knowledge and opinions regarding adverse drug reaction reporting in Northern China.

Pharmacoepidemiol Drug Saf 2010;19:217-222.

46. Tobaiqy M, Stewart D, Helms PJ, Bond C, Lee AJ, Bateman N, McCaig $\mathrm{D}$, McLay J. A pilot study to evaluate a community pharmacy-based monitoring system to identify ADRs associated with paediatric use. Eur J Clin Pharmacol 2010;66(6):627-32.

47. $\quad$ Ashcroft DM, Morecroft C, Parker D, Noyce PR. Likelihood of reporting adverse events in community pharmacy: an experimental study. Qual Saf Health Care 2006;15:48-52.

48. NRLS Quarterly Data Workbook up to September 2012 [online]. Available from URL: http://www.nrls.npsa.nhs.uk/resources/type/datareports/?entryid45=135212 [Accessed 2014 Jan 23]

49. Pharmaceutical Services Negotiating Committee. New Medicines Service [online]. Available from URL:

http://psnc.org.uk/services-commissioning/advanced-services/nms/\#directions [Accessed 2014 Jan 23]

50. Claim and Confirmation for Home Medicines Review Service [online].

Available from URL: http://www.medicareaustralia.gov.au/provider/pbs/fifthagreement/files/4915-1303en.pdf_[Accessed 2014 Jan 23]

51. Jadeja M, McCreedy C. Positive effect of new medicine service on community yellow card reporting. Pharm J 2012; 289:159.

52. Smith MP, Webley SD. Pharmacovigilance teaching in UK undergraduate pharmacy programmes. Pharmacoepidemiol Drug Saf 2013; 22: 223-228.

53. Sardas SS, Akici AA, Dagistanli SD. The knowledge and attitude of the undergraduate students in the faculty of pharmacy towards pharmacovigilance. Drug Saf 2010; 33(10): 930-931.

54. Elkalmi RM, Hassali MA, Ibrahim MI, Widodo RT, Efan QM, Hadi MA. Pharmacy students' knowledge and perceptions about pharmacovigilance in Malaysian public universities. Am J Pharm Ed 2011; 7595): Article 96.

55. American Board of Internal Medicine. Project Professionalism; 1995 [online]. Available from URL:

http://www.abim.org/pdf/publications/professionalism.pdf. [Accessed 2014 May 23] 
56. General Pharmaceutical Council. Approval of courses [online]. Available from URL: http://www.pharmacyregulation.org/education/approvalcourses [Accessed 2014 Jan 23]

57. Stewart D, MacLure K, Paudyal V, Hughes C, Courtney M, McLay J. Non-medical prescribers and pharmacovigilance: participation, competence and future needs. Int J Clin Pharm 2013;35:268-74.

58. Kroger E, Moisan J, Gregoire JP. Billing for cognitive services: understanding Quebec pharmacists' behaviour. Ann Pharmacother 2000;34:309-316.

59. Chan P, Grindrod KA, Bougher D, Pasutto FM, Wilgosh C, Eberhart G, Tsuyuki R. A systematic review of remuneration systems for clinical pharmacy services. Can Pharm J 2009; 141(2):102-112.

60. Rosenthal M. Austin Z, Tsuyuki RT. Are pharmacists the ultimate barrier to pharmacy practice change? Can Pharm J 2010; 143(1):37-42.

61. Austin Z, Gregory PAM, Martin JC. Negotiation of interprofessional culture shock: the experiences of pharmacists who become physicians. J Interprof Care 2007;21:83-93.

62. Blake KB, Madhavan SS. Perceived barriers to provision of medication therapy management services (MTMS) and the likelihood of a pharmacist to work in a pharmacy that provides MTMS. Ann Pharmacother 2010;44:424-31. 63. National Services Scotland. Practitioner services [online]. Available from URL: http://www.psd.scot.nhs.uk/pharmacists/patient-registration.html [Accessed 2014, May 23].

64. Gray B. Ontario pharmaceutical opinion program. Can Pharm J 2013; 146(6): 329-334.

65. Richardson E, Pollock AM. Community pharmacy: moving from dispensing to diagnosis and treatment. Brit Med J 2010;340:1066-1068.

66. Gonzalez-Gonzalez C, Lopez-Gonzalez E, Herdeiro MT, Figueiras A. Strategies to Improve adverse drug reaction reporting: a critical and systematic review. Drug Saf 2013;36(5):317-28. 